\title{
CHARACTERIZATION OF PUMPS FOR IRRIGATION IN CENTRAL CALIFORNIA: POTENTIAL ENERGY SAVINGS
}

\author{
Luis Pérez Urrestarazu and Charles M. Burt \\ Irrigation Training and Research Center \\ California Polytechnic State University, San Luis Obispo, CA 93407-0730 \\ January 2011
}

\section{INTRODUCTION}

The annual agricultural electric pumping usage in California is around 10 million MWh and most of it occurs in the Sacramento and San Joaquin Valleys, where the majority of agriculture is located (Burt et al., 2003).

Pumping costs are often higher than they should be for two reasons: more water is pumped than is necessary, and/or the pumping plant operates inefficiently (either the pump itself is inefficient, or the total dynamic head is greater than needed).

Ideally, new electric overall pumping plant efficiencies (OPPE) should be at least 70 percent (for greater than 25 kilowatts) and every new pumping plant should be tested to verify/determine the starting OPPE. Current practices in the California agricultural irrigation market do not typically guarantee a new OPPE, nor are verification tests performed by the pump vendor or others.

Pumps that are initially efficient can become inefficient through pump wear, changes in groundwater conditions, and changes in the irrigation system (Hanson, 1988). Options for improving OPPE include adjusting impellers, repairing or replacing worn pumps, replacing mismatched pumps, and converting to energy efficient electric motors (Hanson, 2002). Variable frequency drives, while not improving the OPPE, reduce the input $\mathrm{kW}$ by only producing the flow and pressure combination that is required at the moment.

Pumping plants should be evaluated every several years to determine the status of the pump and possible reasons for poor efficiency. Evaluating a pumping plant requires a pump test, during which capacity (flow rate), lift, discharge pressure and input horsepower are measured. Electric utilities such as Pacific Gas and Electric Company have provided such evaluations for over 70 years in California to minimize energy consumption in the irrigation sector. Additional programs have been sponsored by the California Energy Commission (Burt and Howes, 2005).

Though pump repair or replacement can substantially improve performance, energy savings will also depend on management and the design of the irrigation system. To reduce electrical energy use, the kilowatt-hours must decrease because of fewer kilowatts $(\mathrm{kW})$ or less operating time, or both. If the new/repaired pump produces a higher flow rate than before, the hours of operation must be reduced to deliver the same volume; operating the same number of hours can use just as much electricity as before.

Irrigation pumps are typically overdesigned to cope with the worst working conditions (normally peak demands, and low groundwater levels) but this means that in normal operation the pump will use more $\mathrm{kW}$ than necessary for a desired flow rate. In such cases, installing variable frequency drives (VFDs) allows pumps to run at slower speeds in cases of lower demand (pressure or flow rate), requiring less $\mathrm{kW}$ - even though the impeller/bowl efficiency may be lower than at the maximum design flow rate and pressure. High efficiency motors should save 3-5\% of their operating cost, although some motors 
labeled as being "high efficiency" appear to have lower efficiency than standard motors (Burt et al. 2008).

The points above are well known in concept. However, information from large datasets of actual pump performance is difficult to obtain. This paper describes an analysis of over 15,000 electric irrigation pump tests in Central California.

\section{OBJECTIVES}

The analysis of the pump tests had the following objectives:

- Define the common characteristics attributed to pumps with best and worst performance and energy consumption.

- Identify the possible target groups that might benefit from improvements, to obtain better efficiencies and reduce energy consumption.

- $\quad$ Obtain rules for targeting pumps for testing, to achieve the maximum energy savings per number of pumps tested.

- Estimate the potential energy reduction if various groups of pumps are targeted.

\section{METHODOLOGY}

A database of irrigation pump test information was compiled from a variety of sources. Data were from the Salinas, Sacramento and San Joaquin Valleys of California over a 5-year period ending in 2009. Data from two different types of pumps were used: well and non-well (mainly booster pumps). No information was available regarding entrance conditions, well pump column losses, or excess pressure requirements of irrigation systems. Pumps were tested by small independent firms that specialize in pump testing.

The reported well pump OPPE values are lower than an OPPE that might be estimated by only considering the impeller/bowl efficiency and motor efficiency. This is because the Total Dynamic Head (pressure) was estimated to be the sum of only the elevation change (discharge elevation minus the pumping water level) plus the discharge pressure. Column losses, entrance screen losses, and discharge head losses were ignored by the pump testers. Furthermore, the shaft horsepower requirements to overcome shaft bearing losses and thrust bearing losses were not included.

The variables available for comparison included:

- Total dynamic head (TDH, m): The sum of the pumping lift and the discharge head for vertical pumps; discharge minus inlet pressure for booster pumps.

- $\quad$ Measured Flow Rate $(\mathrm{Q}, \mathrm{l} / \mathrm{s})$

- $\quad$ Input power to the motor $(\mathrm{kW})$

- $\quad$ Drawdown (Drdw, m): difference between the pumping water level and the standing water level (only in well pumps)

- $\quad$ Discharge pressure (DPres, bar): pressure on the outlet side of the pump

- Kilowatt-hours per unit volume $\left(\mathrm{kWh} / \mathrm{m}^{3}\right)$ : kilowatt-hours required to pump a cubic meter of water at the operating condition measured.

- Annual energy consumption (MWh/y): Megawatt-hours consumed per year (only available for some pumps). $1 \mathrm{MWh}=1000 \mathrm{kWh}$

- Overall Pumping Plant Efficiency (OPPE, \%): water power generated by the pump (function of the flow rate and reported total dynamic head) divided by input power. 
Data for 12,887 well pumps (902 in Salinas, 497 in Sacramento and 11,488 in San Joaquin Valley) and 2,875 non-well pumps (295 in Salinas, 248 in Sacramento and 2,332 in San Joaquin Valley) were used. Within this dataset, values for annual energy consumption were available for 5,436 well pumps and 896 non-well pumps.

A multivariate cluster variable analysis was performed with Minitab® 16.1 .0 to study the variables' similarity level. In addition, the different variables were compared to each other in order to find correlations and significant trends in the data. Scattered plots were used with function adjustment.

To study the potential energy savings associated with pumps of different characteristics, different groupings were made according to the annual energy consumed, and TDH and Q ranges. With this grouping, comparisons between pumps working at similar conditions are possible. Averages for all the variables were calculated for each group. Pumps with an OPPE below the group average are considered to be potentially improved. The energy saved in these pumps is estimated as the difference between actual energy consumption and the average of the top 25\% of the pump efficiencies within that group.

For example:

Pump with OPPE $=36 \%$

Energy consumption $=398 \mathrm{MWh} /$ year.

The OPPE average of best $25 \%$ performers of the group $=68 \%$

Therefore, the energy savings are estimated as follows, assuming the new pump is operated at the original flow rate and TDH:

New Energy Consumption if “average” $=\frac{\text { Old } O P P E}{\text { New } O P P E} \times$ Present energy consumption

$$
\begin{aligned}
& =\frac{36 \%}{68 \%} \times 398 M W h / y r \\
& =211 \mathrm{MWh} / \mathrm{yr}
\end{aligned}
$$

$$
\begin{aligned}
\text { Savings } & =\text { Original energy consumption }- \text { New energy consumption } \\
& =398 \mathrm{MWh} / \mathrm{yr}-211 \mathrm{MWh} / \mathrm{yr}=187 \mathrm{MWh} / \mathrm{yr}
\end{aligned}
$$

In that way, the total and average potential energy savings are calculated for each group - without considering additional savings that would be possible if the TDH was reduced. An average price for energy of $\$ 0.15$ per $\mathrm{kW}$ was used to obtain the possible money savings in each case.

\section{RESULTS}

Overview facts

The OPPE average value is 53\% for well pumps and 52\% for non-well pumps. This means that the actual OPPE for well pumps is somewhat higher than for non-well pumps if the various bearing, column loss, and other items were considered. These values are similar to those of Burt and Howes (2005 and 2008) where average OPPE values for pumping plants in California were $57.5 \%$ and $55 \%$ respectively. 
Thirty-five percent of well pumps and 51\% of non-well pumps have poor OPPEs (lower than 50\%). Only $6 \%$ of well pumps and $9 \%$ of non-well have OPPEs over $70 \%$.

The total annual energy consumption of the studied pumps is estimated at 724,083 MWh (641,720 MWh for well and 82,363 MWh for non-well pumps) with an average of $118 \mathrm{MWh} /$ year for a well pump and $92 \mathrm{MWh}$ /year for non-well pumps. The average energy consumption per volume of water pumped in the case of well pumps $\left(0.33 \mathrm{kWh} / \mathrm{m}^{3}\right)$ is twice that of non-well pumps $\left(0.16 \mathrm{kWh} / \mathrm{m}^{3}\right)$.

\section{Correlations between variables (all pumps)}

A hierarchical cluster analysis was performed using Minitab ${ }^{\circledR}$ 16.1.0 to study the similarity between variables. The dendrogram shown in Figure 1 is a graphical representation of its results. In this tree-like plot each step of hierarchical clustering is represented as a fusion of two branches which represent the clusters obtained according to the level of similarity found in the variables' values. This analysis showed that $\mathrm{TDH}$ and $\mathrm{kWh} / \mathrm{m}^{3}$ were highly similar. Also, input power and the energy consumption in a year had an analogous behavior. On the other hand, OPPE and Q are more independent variables. This information is useful to reduce the number of variables in order to continue with an analysis. Therefore, OPPE, TDH, Q and MWh/year were selected as key variables.

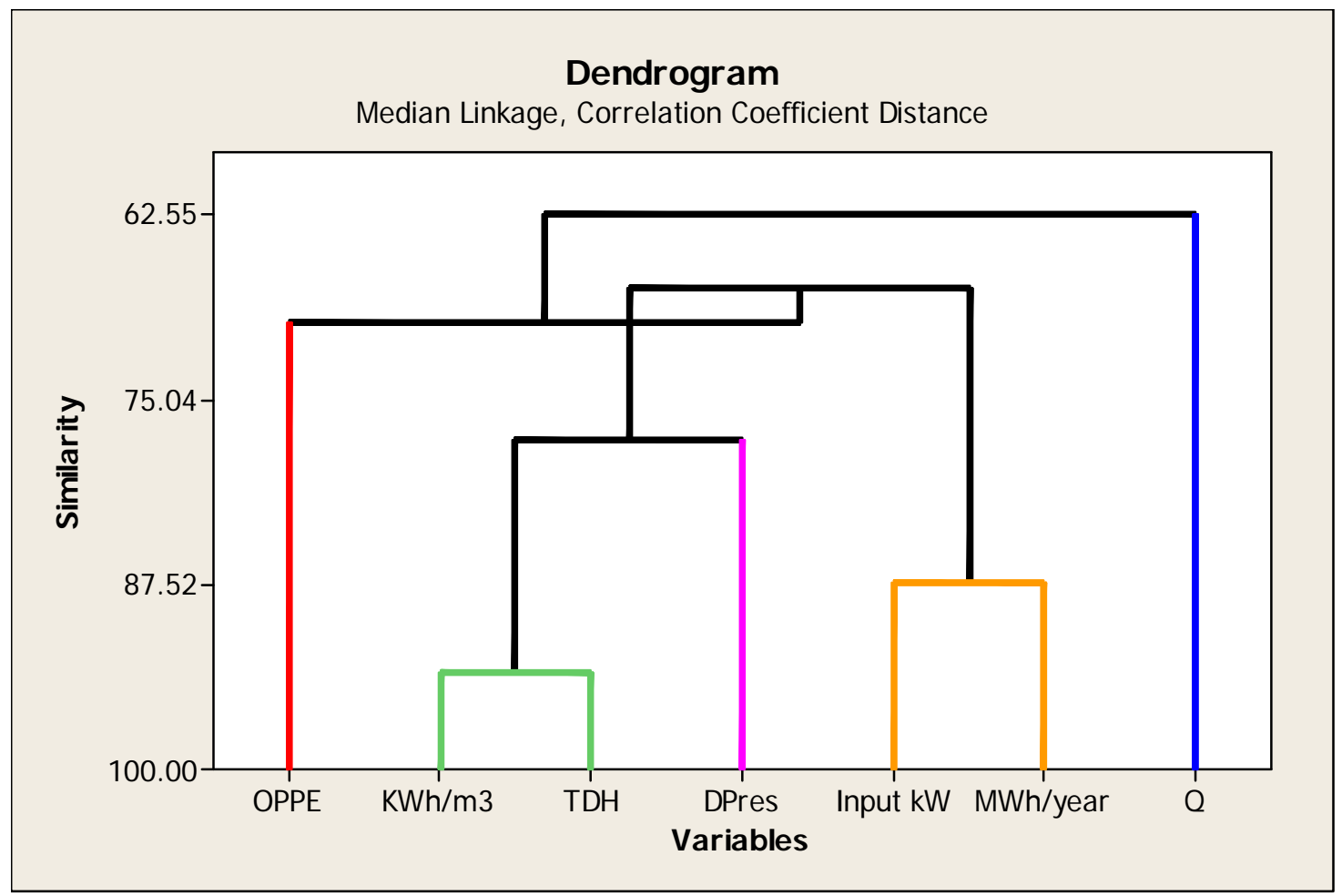

Figure 1. Dendrogram showing similarity between variables

Trends and correlations between variables (well pumps)

OPPE values tended to be better when TDH, Q and input power are high. This pattern is clearer in the case of TDH where 85\% of pumps with OPPE $<50 \%$ have a TDH $<75 \mathrm{~m}$ while $70 \%$ of pumps with OPPE $<30 \%$ have a TDH $<45 \mathrm{~m}$ (Figure 2a). When TDH $>120 \mathrm{~m}$, only 16\% of pumps have an OPPE under $50 \%$. 

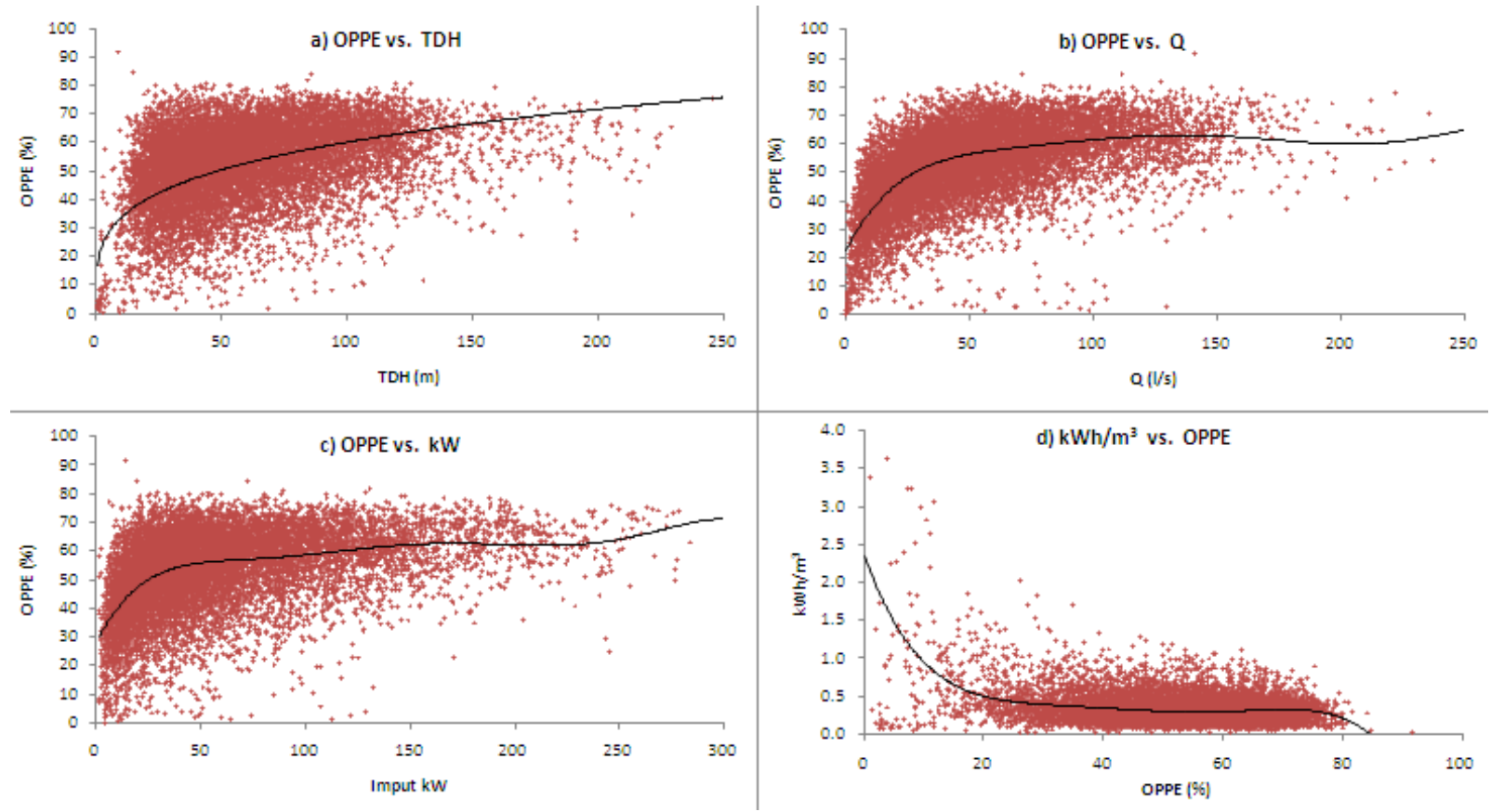

Figure 2. Correlations for well pumps, OPPE (\%) vs. other variables: a) TDH (m); b) Q (l/s); c) input power (kW); d) $\mathbf{k W h} / \mathrm{m}^{3}$

When looking into the relation between OPPE and Q (Figure 2b), small flow rates are frequently associated with lower OPPEs. In fact, 75\% of pumps with OPPE $<50 \%$ have a Q $<50 \mathrm{l} / \mathrm{s}$ while $80 \%$ of pumps with OPPE < 30\% have a flow rate under $25 \mathrm{l} / \mathrm{s}$. Only 11\% of high flow pumps (over $125 \mathrm{l} / \mathrm{s}$ ) have OPPEs below 50\%. It is observed that when Q is high, even when TDH values are low, OPPE values are better.

Once again, low values for the input power are related to poor OPPEs (Figure 2c): 76\% of pumps with OPPEs $<50 \%$ have an input power below $50 \mathrm{~kW}$ and only $9 \%$ of pumps with more than $150 \mathrm{~kW}$ show an OPPE under $50 \%$. High values of $\mathrm{kWh} / \mathrm{m}^{3}$ are related with low OPPE (all the pumps consuming more than $1.2 \mathrm{kWh} / \mathrm{m}^{3}$ have OPPE below $50 \%$, but no trend is observed for pumps with less than 0.1 $\mathrm{kWh} / \mathrm{m}^{3}$ (Figure 2d). Nevertheless, pumps with very high efficiency show lower consumption per volume pumped. Increasing trends are not so clear for OPPE vs. drawdown and discharge pressure.

Obvious increasing trends are observed when relating annual energy consumption (MWh/year) with $\mathrm{TDH}, \mathrm{Q}$ and $\mathrm{kWh} / \mathrm{m}^{3}$ (Figure 3). However, high values of energy consumption occur in certain intervals (75-150 $\mathrm{m}$ for TDH; 100-125 l/s for Q, and 0.3-0.6 kWh/m ${ }^{3}$ ). This situation can be better observed in the contour plot provided (Figure 4). Therefore, bigger pumps lifting more flow with high TDH do not necessarily consume more energy during the year as they are not usually operating so many hours. 

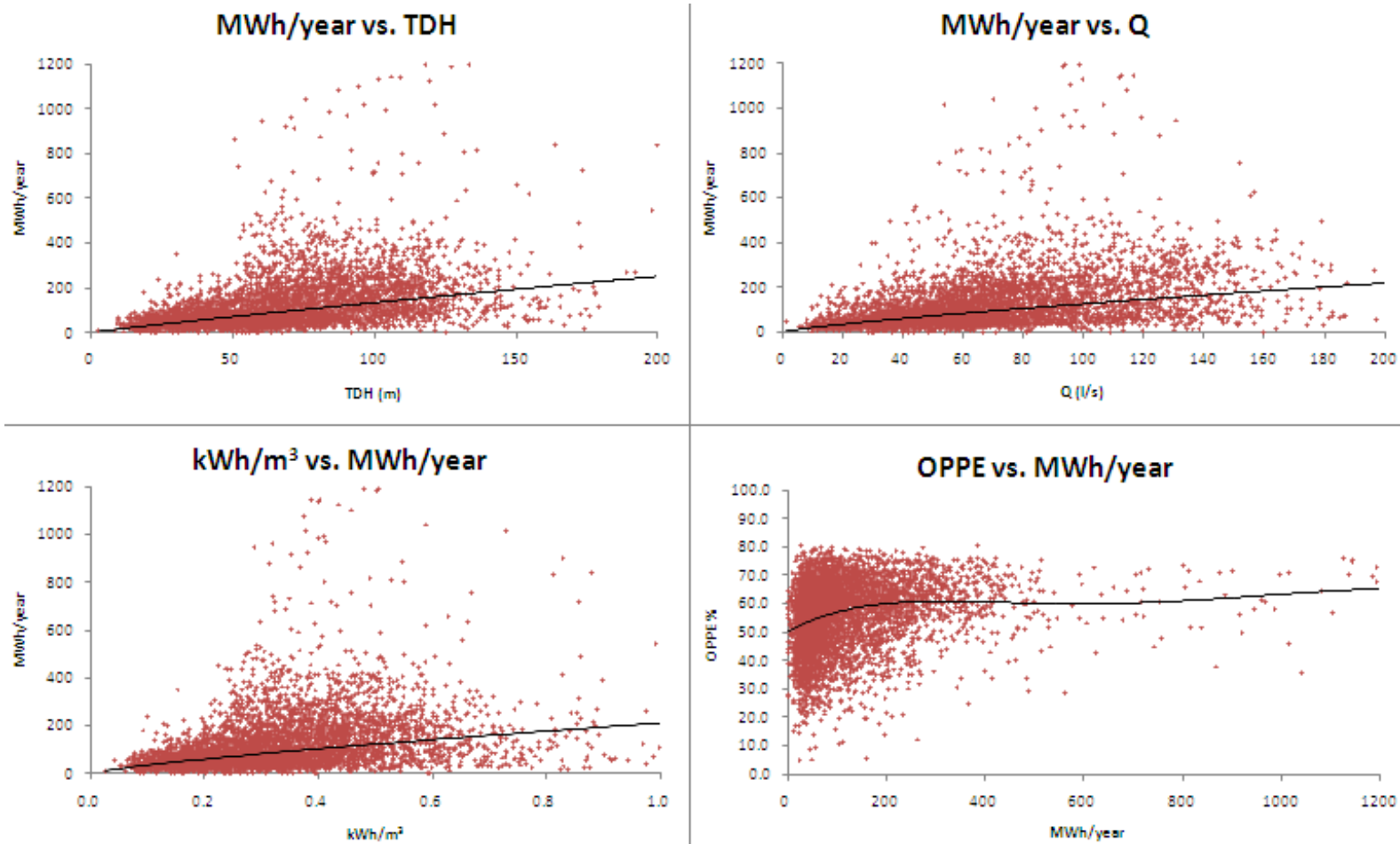

Figure 3. Correlations for well pumps, energy consumption (MWh/year) vs. other variables: a) TDH (m); b) Q (l/s); c) input power per volume pumped $\left(\mathrm{kWh} / \mathrm{m}^{3}\right)$; d) OPPE (\%)

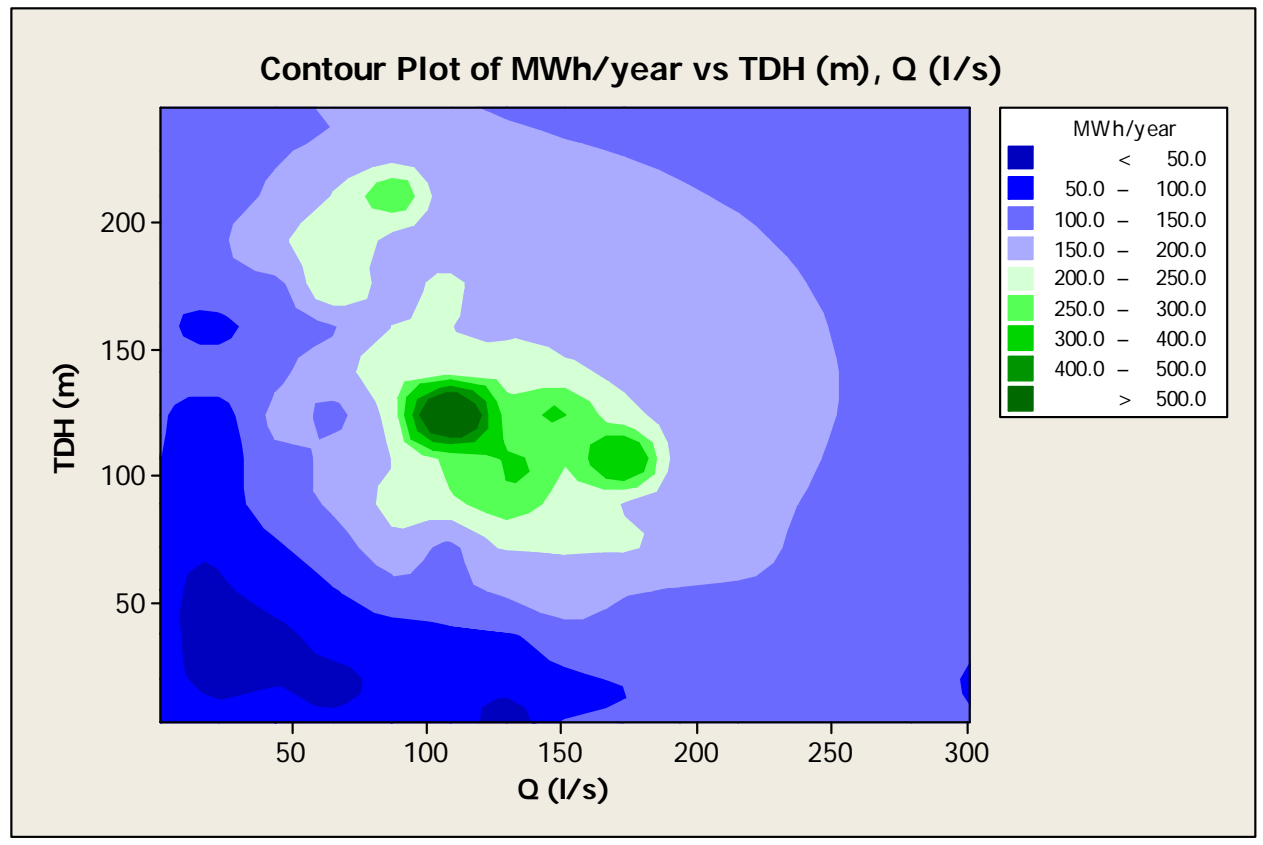

Figure 4. Contour plot for well pumps, TDH (m) vs. Q (l/s) arranged by energy consumption (MWh/year) 
Pumps consuming a lot of energy do not necessarily have a high OPPE, though small efficiency values are dominant in the case of low energy consumption (92\% of pumps with OPPE $<50 \%$ consume less than $200 \mathrm{MWh} /$ year).

Trends and correlations between variables (non-well pumps)

In non-well pumps, the trends are not so clear as in well pumps though again, higher values of TDH, Q and input kW correspond to better OPPE (Figure 5). Only 19\% of pumps with TDH over $60 \mathrm{~m}$ and 38\% of pumps with Q $>300 \mathrm{l} / \mathrm{s}$ have OPPE $<50 \%$. But $43 \%$ of pumps with TDH below $60 \mathrm{~m}$ and $40 \%$ of pumps with $\mathrm{Q}<300 \mathrm{l} / \mathrm{s}$ have OPPE $<50 \%$. That means that TDH values are more related with OPPE than Q. Also, only 15\% of pumps with input power over $100 \mathrm{~kW}$ have OPPE $<50 \%$.

In this case, high values of $\mathrm{kWh} / \mathrm{m}^{3}$ are not necessary related with lower OPPE (Figure $5 \mathrm{~d}$ ). Anyway, only $10 \%$ of pumps consuming more than $1 \mathrm{kWh} / \mathrm{m}^{3}$ have an OPPE over $50 \%$.

For non-well pumps, the patterns when relating the variables with the annual consumption are not obvious (Figure 6). Most pumps with TDH < $60 \mathrm{~m}$ (82\%) consume less than $100 \mathrm{MWh} /$ year but only $46 \%$ of pumps with $\mathrm{TDH}>60 \mathrm{~m}$ use less than $100 \mathrm{MWh} /$ year. It is interesting to note that high annual consumptions are related to lower flows (70\% of pumps consuming more than $200 \mathrm{MWh} /$ year have Q < $300 \mathrm{l} / \mathrm{s}$ ). No relation is found between annual power consumption and energy use per volume pumped. $77 \%$ of pumps consuming more than $100 \mathrm{MWh} /$ year have OPPE $>50 \%$ while $59 \%$ of pumps using less than $100 \mathrm{MWh} /$ year have OPPE > 50\%.
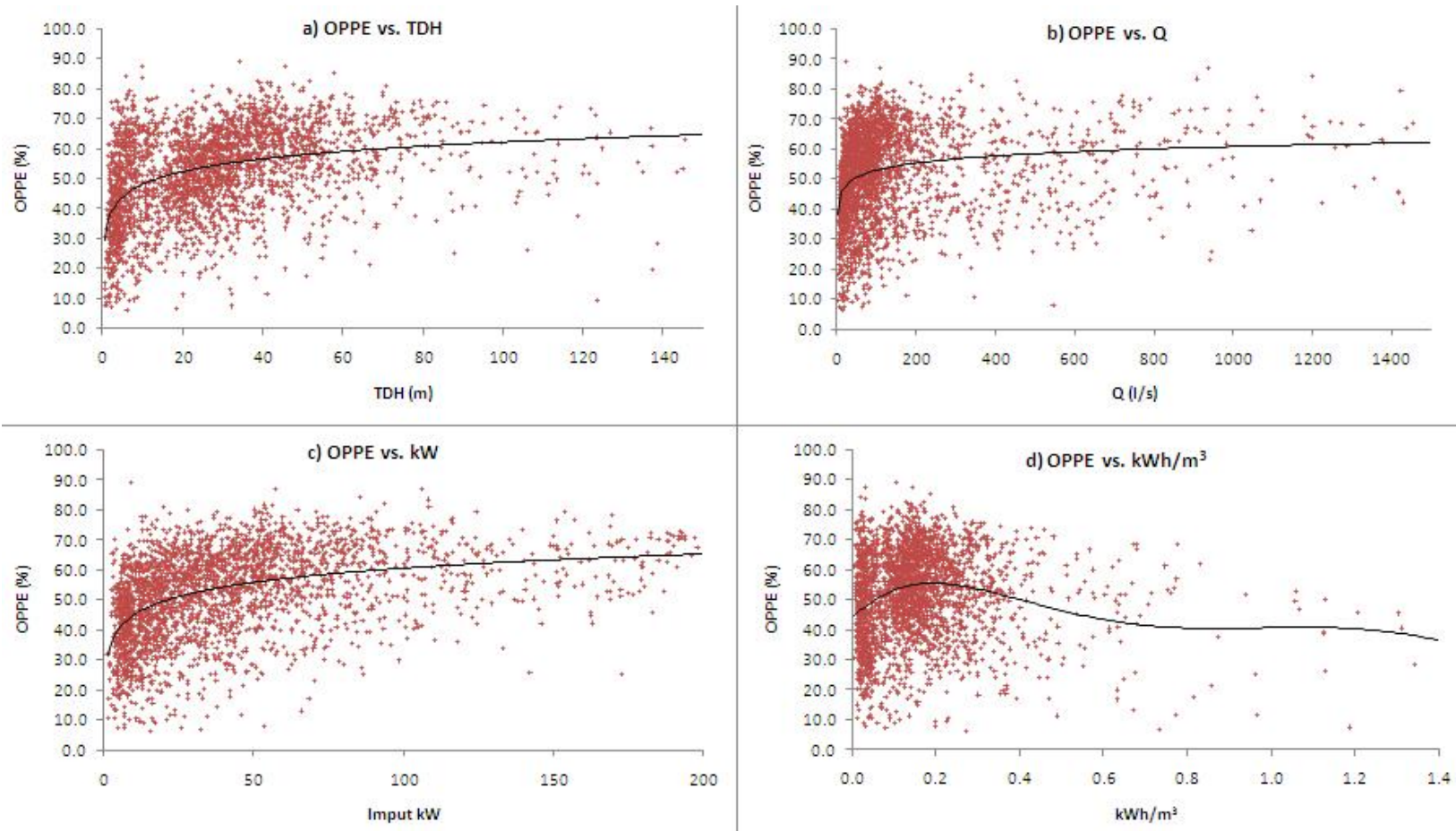

Figure 5. Correlations for non-well pumps, OPPE (\%) vs. other variables: a) TDH (m); b) Q (l/s); c) input power (kW); d) $\mathbf{k W h} / \mathrm{m}^{3}$ 

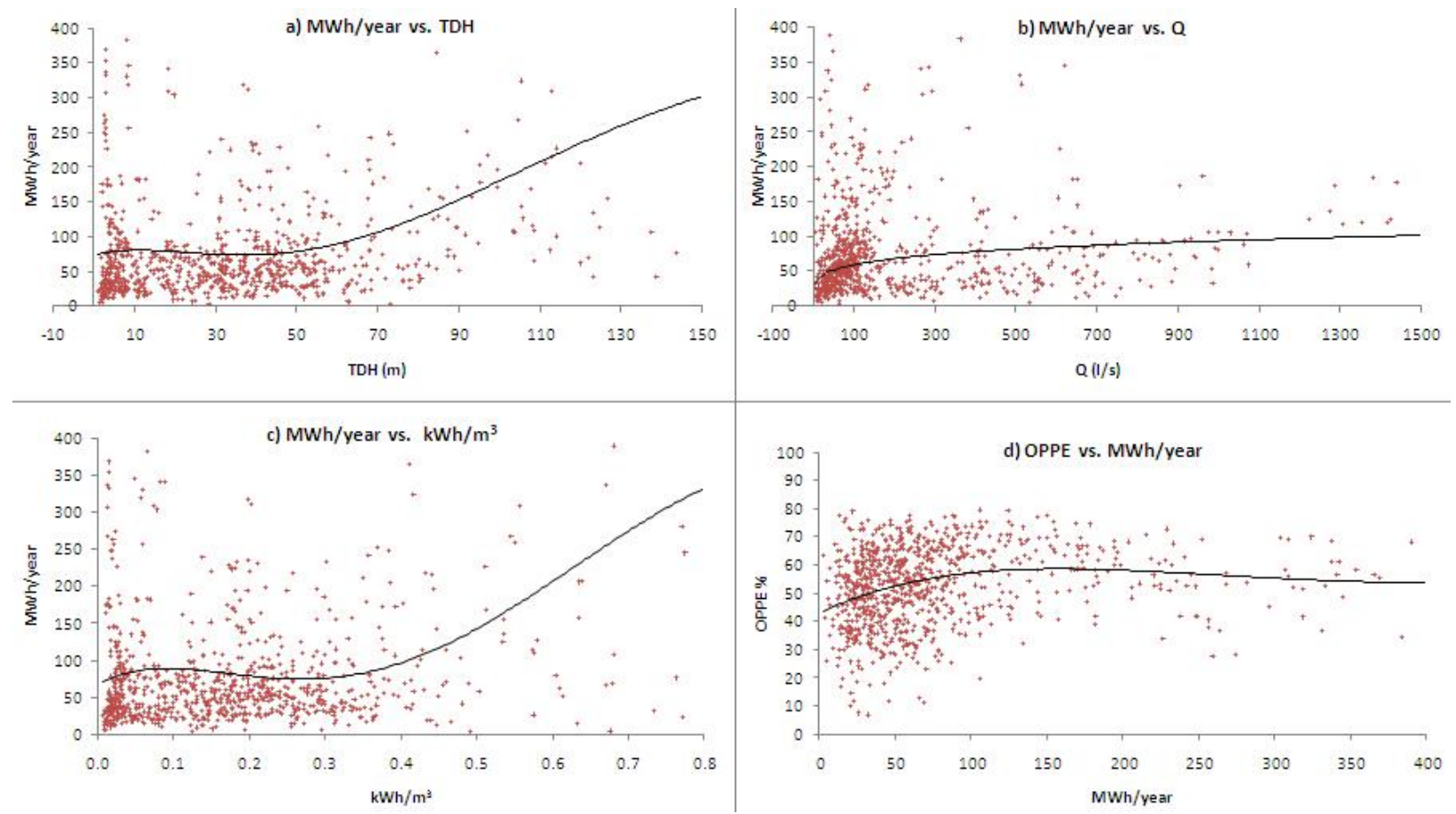

Figure 6. Correlations for non-well pumps, energy consumption (MWh/year) vs. other variables: a) TDH (m); b) Q $(\mathrm{l} / \mathrm{s}) ; \mathrm{c})$ input power per volume pumped $\left.\left(\mathrm{kWh} / \mathrm{m}^{3}\right) ; \mathrm{d}\right)$ OPPE (\%)

Figure 7 shows the conjunctive effect of TDH and Q in annual power consumption. When both variables are small, the consumption also remains low. But for high TDH and low Q or vice versa higher consumptions are observed, as one would expect.

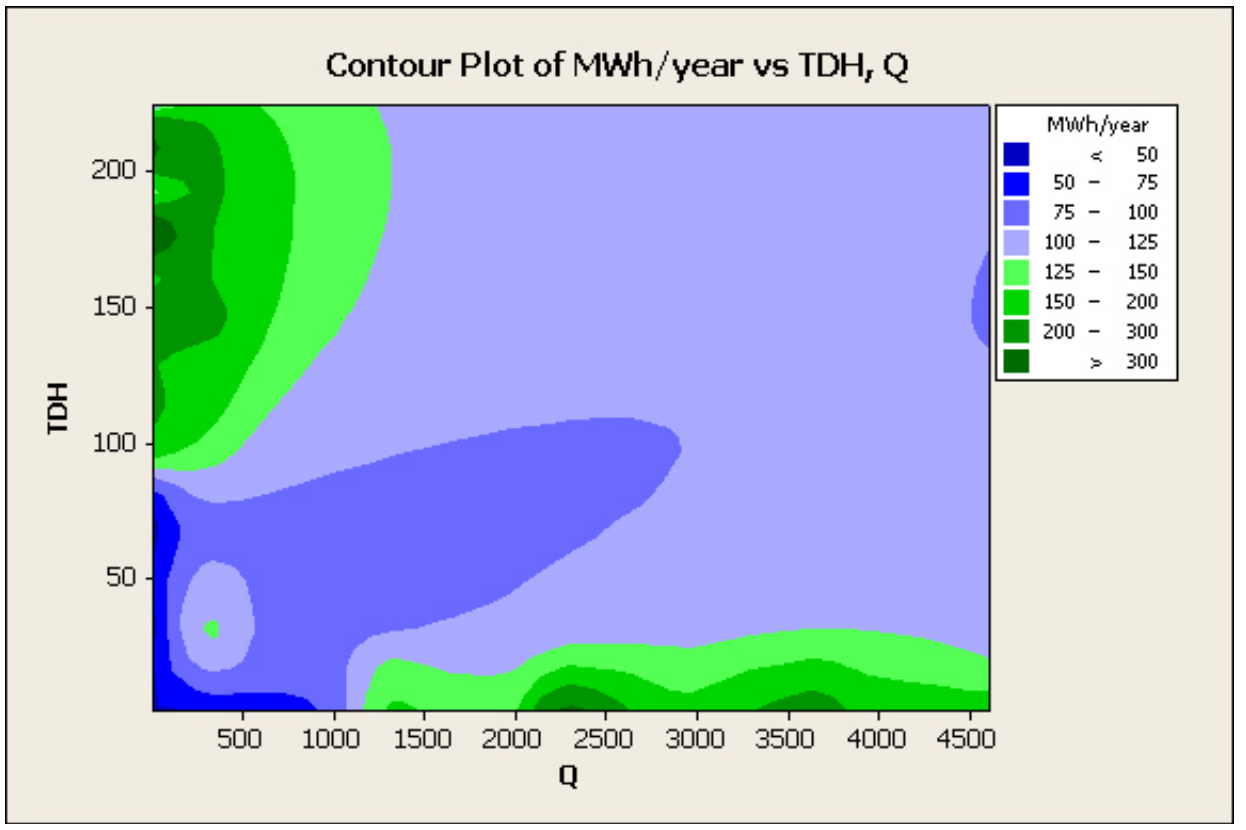

Figure 7. Contour plot for non-well pumps, TDH (m) vs. Q (l/s) arranged by energy consumption (MWh/year) 
Energy savings analysis

Pumps work in different conditions. Their operation and therefore their efficiency and energy consumption are in some way affected by these working circumstances. For this reason, categories were made according to annual energy consumption, TDH, and Q to determine the possible energy savings that might be achieved. This involves comparing the performance of a pump against the average performance in the same category.

The category ranges were selected according to the distribution of number of pumps with certain values for the variables considered.

Table 1 shows, for each category of well pump, the average values of OPPE and MWh/year, the number of pumps in the group, the percentage of pumps which can be improved, the total potential energy savings and the average per pump and the money saved in each case.

The above-mentioned relationships between TDH and Q with OPPE are confirmed: average values of OPPE are better when TDH and Q are higher.

Table 1. Potential energy savings for each category in well pumps

\begin{tabular}{|c|c|c|c|c|c|c|c|c|c|c|}
\hline MWh/y & $\mathrm{TDH}(\mathrm{m})$ & $\begin{array}{c}Q \\
(1 / s)\end{array}$ & $\begin{array}{l}\text { Av. } \\
\text { OPPE } \\
(\%)\end{array}$ & $\begin{array}{c}\text { Av. } \\
\text { MWh/y }\end{array}$ & $\begin{array}{l}\text { MWh } \\
\text { saved }\end{array}$ & $\begin{array}{c}\text { Av. } \\
\text { MWh } \\
\text { saved }\end{array}$ & $\begin{array}{c}\text { Number } \\
\text { of } \\
\text { pumps }\end{array}$ & $\begin{array}{c}\% \text { of } \\
\text { pumps } \\
\text { achieving } \\
\text { savings }\end{array}$ & $\begin{array}{c}\text { \$ saved } \\
\text { per year } \\
\text { (average } \\
\text { case) }\end{array}$ & $\begin{array}{l}\$ \text { saved per } \\
\text { year (total) }\end{array}$ \\
\hline \multirow{6}{*}{$>800$} & $60-75$ & $>100$ & 52.7 & 921.8 & 554.7 & 138.7 & 5 & 80.0 & $\$ 20,801$ & $\$ 83,204$ \\
\hline & $75-90$ & $>100$ & 59.4 & 1041.5 & 777.3 & 194.3 & 5 & 80.0 & $\$ 29,147$ & $\$ 116,589$ \\
\hline & \multirow{2}{*}{$90-120$} & $<100$ & 61.3 & 973.1 & 784.0 & 196.0 & 5 & 80.0 & $\$ 29,400$ & $\$ 117,598$ \\
\hline & & $>100$ & 69.3 & 1170.8 & 1056.7 & 105.7 & 11 & 90.9 & $\$ 15,850$ & $\$ 158,503$ \\
\hline & \multirow{2}{*}{$>120$} & $<100$ & 64.7 & 948.3 & 784.7 & 112.1 & 8 & 87.5 & $\$ 16,816$ & $\$ 117,710$ \\
\hline & & $>100$ & 66.7 & 1357.5 & 329.7 & 109.9 & 4 & 75.0 & $\$ 16,486$ & $\$ 49,459$ \\
\hline \multirow{10}{*}{$400-800$} & \multirow{2}{*}{$<60$} & $<100$ & 47.4 & 520.4 & 415.7 & 103.9 & 5 & 80.0 & $\$ 15,588$ & $\$ 62,351$ \\
\hline & & $>100$ & 60.7 & 472.8 & 258.7 & 51.7 & 6 & 83.3 & $\$ 7,761$ & $\$ 38,804$ \\
\hline & \multirow{2}{*}{$60-75$} & $<100$ & 51.7 & 527.9 & 1023.5 & 93.0 & 12 & 91.7 & $\$ 13,957$ & $\$ 153,525$ \\
\hline & & $>100$ & 57.2 & 512.1 & 1065.8 & 106.6 & 12 & 83.3 & $\$ 15,987$ & $\$ 159,871$ \\
\hline & \multirow{2}{*}{$75-90$} & $<100$ & 63.1 & 460.9 & 730.6 & 48.7 & 17 & 88.2 & $\$ 7,306$ & $\$ 109,594$ \\
\hline & & $>100$ & 63.1 & 444.7 & 628.5 & 57.1 & 12 & 91.7 & $\$ 8,571$ & $\$ 94,280$ \\
\hline & \multirow{2}{*}{$90-120$} & $<100$ & 60.7 & 502.7 & 1888.0 & 89.9 & 24 & 87.5 & $\$ 13,485$ & $\$ 283,194$ \\
\hline & & $>100$ & 64.7 & 518.2 & 485.8 & 54.0 & 10 & 90.0 & $\$ 8,097$ & $\$ 72,875$ \\
\hline & \multirow{2}{*}{$>120$} & $<100$ & 60.6 & 576.0 & 823.7 & 117.7 & 8 & 87.5 & $\$ 17,652$ & $\$ 123,562$ \\
\hline & & $>100$ & 71.2 & 447.9 & 133.1 & 22.2 & 7 & 85.7 & $\$ 3,327$ & $\$ 19,964$ \\
\hline \multirow{10}{*}{$300-400$} & \multirow{2}{*}{$<60$} & $<100$ & 51.3 & 320.2 & 209.8 & 52.4 & 5 & 80.0 & $\$ 7,866$ & $\$ 31,463$ \\
\hline & & $>100$ & 61.0 & 336.3 & 142.4 & 23.7 & 7 & 85.7 & $\$ 3,559$ & $\$ 21,356$ \\
\hline & \multirow{2}{*}{$60-75$} & $<100$ & 58.0 & 353.1 & 1320.2 & 69.5 & 21 & 90.5 & $\$ 10,422$ & $\$ 198,026$ \\
\hline & & $>100$ & 64.3 & 345.1 & 631.9 & 42.1 & 17 & 88.2 & $\$ 6,319$ & $\$ 94,788$ \\
\hline & \multirow{2}{*}{$75-90$} & $<100$ & 58.0 & 335.6 & 782.0 & 52.1 & 16 & 93.8 & $\$ 7,820$ & $\$ 117,301$ \\
\hline & & $>100$ & 65.1 & 344.8 & 963.4 & 45.9 & 23 & 91.3 & $\$ 6,881$ & $\$ 144,509$ \\
\hline & \multirow{2}{*}{$90-120$} & $<100$ & 55.4 & 344.8 & 1345.7 & 84.1 & 18 & 88.9 & $\$ 12,616$ & $\$ 201,855$ \\
\hline & & $>100$ & 63.8 & 344.4 & 2295.2 & 47.8 & 55 & 87.3 & $\$ 7,172$ & $\$ 344,278$ \\
\hline & \multirow{2}{*}{$>120$} & $<100$ & 64.8 & 335.9 & 446.6 & 63.8 & 8 & 87.5 & $\$ 9,570$ & $\$ 66,988$ \\
\hline & & $>100$ & 69.5 & 363.9 & 282.1 & 23.5 & 13 & 92.3 & $\$ 3,527$ & $\$ 42,320$ \\
\hline \multirow{3}{*}{$200-300$} & \multirow{2}{*}{$<60$} & $<100$ & 51.3 & 234.7 & 766.0 & 76.6 & 12 & 83.3 & $\$ 11,490$ & $\$ 114,897$ \\
\hline & & $>100$ & 57.2 & 239.5 & 1074.4 & 39.8 & 31 & 87.1 & $\$ 5,969$ & $\$ 161,165$ \\
\hline & $60-75$ & $<100$ & 56.5 & 235.9 & 2233.8 & 42.1 & 58 & 91.4 & $\$ 6,322$ & $\$ 335,065$ \\
\hline
\end{tabular}




\begin{tabular}{|c|c|c|c|c|c|c|c|c|c|c|}
\hline & & $>100$ & 61.8 & 245.8 & 1544.6 & 40.6 & 44 & 86.4 & $\$ 6,097$ & $\$ 231,683$ \\
\hline & \multirow{2}{*}{$75-90$} & $<100$ & 54.3 & 236.1 & 3071.7 & 55.8 & 62 & 88.7 & $\$ 8,377$ & $\$ 460,761$ \\
\hline & & $>100$ & 64.6 & 247.9 & 2657.2 & 40.3 & 77 & 85.7 & $\$ 6,039$ & $\$ 398,573$ \\
\hline & \multirow{2}{*}{$90-120$} & $<100$ & 57.7 & 231.6 & 4106.8 & 39.1 & 117 & 89.7 & $\$ 5,867$ & $\$ 616,021$ \\
\hline & & $>100$ & 67.1 & 255.8 & 1902.6 & 28.0 & 81 & 84.0 & $\$ 4,197$ & $\$ 285,390$ \\
\hline & \multirow{2}{*}{$>120$} & $<100$ & 58.4 & 243.1 & 1750.7 & 38.1 & 51 & 90.2 & $\$ 5,709$ & $\$ 262,605$ \\
\hline & & $>100$ & 71.9 & 262.5 & 134.5 & 16.8 & 9 & 88.9 & $\$ 2,522$ & $\$ 20,179$ \\
\hline \multirow{10}{*}{$100-200$} & \multirow{2}{*}{$<60$} & $<100$ & 51.0 & 134.3 & 5558.9 & 33.1 & 190 & 88.4 & $\$ 4,963$ & $\$ 833,839$ \\
\hline & & $>100$ & 58.7 & 135.8 & 3136.9 & 22.7 & 154 & 89.6 & $\$ 3,410$ & $\$ 470,542$ \\
\hline & \multirow{2}{*}{$60-75$} & $<100$ & 55.1 & 141.2 & 5652.8 & 29.9 & 208 & 90.9 & $\$ 4,486$ & $\$ 847,924$ \\
\hline & & $>100$ & 64.6 & 149.8 & 1093.6 & 17.6 & 69 & 89.9 & $\$ 2,646$ & $\$ 164,045$ \\
\hline & \multirow{2}{*}{$75-90$} & $<100$ & 56.9 & 146.8 & 5142.2 & 31.5 & 186 & 87.6 & $\$ 4,732$ & $\$ 771,337$ \\
\hline & & $>100$ & 68.4 & 156.0 & 362.7 & 16.5 & 26 & 84.6 & $\$ 2,473$ & $\$ 54,404$ \\
\hline & \multirow{2}{*}{$90-120$} & $<100$ & 59.4 & 144.5 & 6403.1 & 27.5 & 263 & 88.6 & $\$ 4,122$ & $\$ 960,458$ \\
\hline & & $>100$ & 68.2 & 167.5 & 734.5 & 21.0 & 41 & 85.4 & $\$ 3,148$ & $\$ 110,169$ \\
\hline & \multirow{2}{*}{$>120$} & $<100$ & 61.8 & 141.7 & 2067.7 & 23.8 & 99 & 87.9 & $\$ 3,565$ & $\$ 310,158$ \\
\hline & & $>100$ & 73.3 & 160.4 & 33.3 & 8.3 & 5 & 80.0 & $\$ 1,248$ & $\$ 4,993$ \\
\hline \multirow{6}{*}{$50-100$} & \multirow{2}{*}{$<45$} & $<100$ & 51.1 & 67.8 & 5545.6 & 16.3 & 378 & 89.9 & $\$ 2,447$ & $\$ 831,846$ \\
\hline & & $>100$ & 56.5 & 73.0 & 2570.5 & 15.0 & 192 & 89.1 & $\$ 2,255$ & $\$ 385,573$ \\
\hline & \multirow{2}{*}{$45-75$} & $<100$ & 56.5 & 70.7 & 7850.7 & 14.2 & 615 & 89.9 & $\$ 2,129$ & $\$ 1,177,608$ \\
\hline & & $>100$ & 65.6 & 83.3 & 378.7 & 11.1 & 39 & 87.2 & $\$ 1,671$ & $\$ 56,806$ \\
\hline & $75-100$ & $<100$ & 59.1 & 74.9 & 3426.0 & 14.6 & 267 & 87.6 & $\$ 2,196$ & $\$ 513,897$ \\
\hline & $>100$ & $<100$ & 60.5 & 77.9 & 1480.1 & 12.7 & 129 & 90.7 & $\$ 1,898$ & $\$ 222,022$ \\
\hline \multirow{8}{*}{$<50$} & \multirow{2}{*}{$<45$} & $<100$ & 50.9 & 32.9 & 6221.5 & 7.9 & 875 & 89.5 & $\$ 1,192$ & $\$ 933,222$ \\
\hline & & $>100$ & 58.0 & 37.0 & 485.9 & 6.8 & 79 & 89.9 & $\$ 1,027$ & $\$ 72,892$ \\
\hline & \multirow{2}{*}{$45-75$} & $<100$ & 54.5 & 34.4 & 3652.3 & 6.8 & 594 & 90.1 & $\$ 1,024$ & $\$ 547,852$ \\
\hline & & $>100$ & 63.4 & 20.2 & 13.2 & 2.2 & 8 & 75.0 & $\$ 329$ & $\$ 1,976$ \\
\hline & $75-100$ & $<100$ & 55.9 & 35.8 & 738.7 & 7.5 & 113 & 87.6 & $\$ 1,119$ & $\$ 110,808$ \\
\hline & $>100$ & $<100$ & 55.2 & 31.3 & 163.6 & 6.8 & 29 & 82.8 & $\$ 1,023$ & $\$ 24,547$ \\
\hline & Averages & & & & & 49.6 & 5435 & 86.9 & $\$ 7,442$ & \\
\hline & Total & & & & 102114.8 & & & & & $\$ 15,317,221$ \\
\hline
\end{tabular}

Potential energy savings are obviously much higher for the pumps with more annual power consumption. In fact, by only targeting 131 pumps over $400 \mathrm{MWh} /$ year (2.5\% of total number of well pumps), $12 \%$ of total savings can be achieved, as the average saved per pump is high (100 MWh/year/pump).

It is also important to pay attention to the percentage of pumps with potential savings as this can give an idea of which categories have worse performance. 
Table 2. Potential energy savings for each category in non-well pumps

\begin{tabular}{|c|c|c|c|c|c|c|c|c|c|c|}
\hline MWh/year & $\mathrm{Q}(\mathrm{l} / \mathrm{s})$ & $\begin{array}{l}\text { TDH } \\
(\mathrm{m}) \\
\end{array}$ & $\begin{array}{c}\text { Av. } \\
\text { OPPE } \\
(\%) \\
\end{array}$ & $\begin{array}{c}\text { Av. } \\
\text { MWh/y }\end{array}$ & $\begin{array}{l}\text { MWh } \\
\text { saved }\end{array}$ & $\begin{array}{l}\text { Av. } \\
\text { MWh } \\
\text { saved }\end{array}$ & $\begin{array}{c}\text { Number } \\
\text { of } \\
\text { pumps }\end{array}$ & $\begin{array}{c}\% \text { of } \\
\text { pumps } \\
\text { achieving } \\
\text { savings }\end{array}$ & $\begin{array}{c}\text { \$ saved } \\
\text { per year } \\
\text { (average } \\
\text { case) }\end{array}$ & $\begin{array}{l}\$ \text { saved per } \\
\text { year (total) }\end{array}$ \\
\hline \multirow{6}{*}{$>300$} & $<60$ & $>30$ & 52.8 & 488.8 & 1853.9 & 154.5 & 13 & 92.3 & $\$ 23,174$ & $\$ 278,091$ \\
\hline & $60-130$ & $>30$ & 59.7 & 637.4 & 448.7 & 89.7 & 7 & 71.4 & $\$ 13,460$ & $\$ 67,302$ \\
\hline & $130-250$ & $>30$ & 53.9 & 398.6 & 179.2 & 35.8 & 5 & 80.0 & $\$ 5,375$ & $\$ 26,876$ \\
\hline & \multirow{2}{*}{$250-500$} & $<30$ & 54.2 & 357.7 & 538.2 & 89.7 & 6 & 83.3 & $\$ 13,454$ & $\$ 80,724$ \\
\hline & & $>30$ & 69.3 & 551.1 & 156.2 & 31.2 & 6 & 83.3 & $\$ 4,686$ & $\$ 23,433$ \\
\hline & $>500$ & $<30$ & 50.2 & 438.2 & 992.3 & 99.2 & 11 & 90.9 & $\$ 14,885$ & $\$ 148,849$ \\
\hline \multirow{6}{*}{$100-300$} & $<60$ & $>30$ & 55.8 & 166.1 & 1284.8 & 45.9 & 35 & 80.0 & $\$ 6,883$ & $\$ 192,727$ \\
\hline & $60-130$ & $>30$ & 63.2 & 156.6 & 1193.4 & 27.8 & 50 & 86.0 & $\$ 4,163$ & $\$ 179,012$ \\
\hline & \multirow{2}{*}{$130-250$} & $<30$ & 56.9 & 189.2 & 81.2 & 27.1 & 4 & 75.0 & $\$ 4,060$ & $\$ 12,180$ \\
\hline & & $>30$ & 64.4 & 171.4 & 436.0 & 20.8 & 23 & 91.3 & $\$ 3,114$ & $\$ 65,397$ \\
\hline & $250-500$ & $<30$ & 53.0 & 141.2 & 484.0 & 44.0 & 13 & 84.6 & $\$ 6,600$ & $\$ 72,604$ \\
\hline & $>500$ & $<30$ & 51.6 & 162.7 & 1576.9 & 46.4 & 39 & 87.2 & $\$ 6,957$ & $\$ 236,529$ \\
\hline \multirow{8}{*}{$50-100$} & \multirow{2}{*}{$<60$} & $<30$ & 40.4 & 66.8 & 163.6 & 32.7 & 6 & 83.3 & $\$ 4,909$ & $\$ 24,545$ \\
\hline & & $>30$ & 52.7 & 65.2 & 842.3 & 15.9 & 61 & 86.9 & $\$ 2,384$ & $\$ 126,345$ \\
\hline & \multirow{2}{*}{$60-130$} & $<30$ & 45.1 & 65.3 & 682.7 & 19.5 & 40 & 87.5 & $\$ 2,926$ & $\$ 102,410$ \\
\hline & & $>30$ & 59.0 & 70.4 & 1228.8 & 14.0 & 101 & 87.1 & $\$ 2,095$ & $\$ 184,327$ \\
\hline & \multirow{2}{*}{$130-250$} & $<30$ & 54.2 & 70.1 & 392.4 & 17.8 & 25 & 88.0 & $\$ 2,675$ & $\$ 58,859$ \\
\hline & & $>30$ & 68.6 & 83.8 & 68.2 & 9.7 & 8 & 87.5 & $\$ 1,460$ & $\$ 10,223$ \\
\hline & $250-500$ & $<30$ & 50.4 & 71.6 & 519.9 & 20.0 & 29 & 89.7 & $\$ 3,000$ & $\$ 77,987$ \\
\hline & $>500$ & $<30$ & 55.5 & 75.7 & 681.3 & 20.0 & 40 & 85.0 & $\$ 3,006$ & $\$ 102,195$ \\
\hline \multirow{9}{*}{$<50$} & \multirow{2}{*}{$<60$} & $<30$ & 40.5 & 23.9 & 231.6 & 7.7 & 35 & 85.7 & $\$ 1,158$ & $\$ 34,742$ \\
\hline & & $>30$ & 50.6 & 31.4 & 1101.5 & 8.7 & 141 & 89.4 & $\$ 1,311$ & $\$ 165,220$ \\
\hline & \multirow{2}{*}{$60-130$} & $<30$ & 47.7 & 31.2 & 524.2 & 9.7 & 59 & 91.5 & $\$ 1,456$ & $\$ 78,633$ \\
\hline & & $>30$ & 61.3 & 39.9 & 87.5 & 6.3 & 16 & 87.5 & $\$ 938$ & $\$ 13,125$ \\
\hline & $130-250$ & $<30$ & 44.8 & 27.7 & 302.6 & 8.0 & 44 & 86.4 & $\$ 1,194$ & $\$ 45,383$ \\
\hline & $250-500$ & $<30$ & 53.0 & 30.6 & 281.6 & 6.4 & 48 & 91.7 & $\$ 960$ & $\$ 42,246$ \\
\hline & $>500$ & $<30$ & 53.5 & 32.0 & 253.5 & 8.7 & 32 & 90.6 & $\$ 1,311$ & $\$ 38,024$ \\
\hline & Averages & & & & & 34.0 & 897.00 & 86.0 & $\$ 5,096$ & \\
\hline & Total & & & & 16586.6 & & & & & $\$ 2,487,988$ \\
\hline
\end{tabular}

The grouping of data provides some other interesting insights. For instance, within the same annual consumption category, pumps with flow higher than $100 \mathrm{l} / \mathrm{s}$ on average have more energy consumption than those with less flow, even if the TDH is much higher. As an example, the average energy consumption for pumps in the range of 200-300 MWh/year with TDH $<60 \mathrm{~m}$ and Q $>100 \mathrm{l} / \mathrm{s}$ is 240 MWh/year while pumps with $\mathrm{Q}<100$ l/s and TDH between 75-90 and 90-120 m consume 236 and 231 MWh/year.

Table 2 shows the same information for non-well pumps. In this case, more divisions have been made according to $\mathrm{Q}$ values as the range is wider than in the case of well pumps. Again, targeting pumps over $300 \mathrm{MWh} /$ year would result in higher savings: action taken on only 41 pumps (4\% of the total) would achieve $25 \%$ of total potential savings. Higher savings seem to be expected in the groups of pumps with low Q and high TDH.

According to this analysis, energy savings of more than 102,100 MWh/year could be achieved for well pumps, with an average per pump of $49 \mathrm{MWh} /$ year. In the case of non-well pumps, the total potential 
savings are over $16500 \mathrm{MWh} /$ year and the average savings for each pump are $34 \mathrm{MWh} /$ year. Hence, more energy can be saved per pump targeting well pumps.

Therefore, if the pump performance is improved to meet the average OPPE of each group, around $\$ 7,400$ year in savings are obtained per well pump and \$5,000/year per non-well pump. These savings will depend on the result of the improvement and the price of energy. Whether the investment will be worthy or not depends on the cost of the improvement. Sometimes small repairs help to improve the performance of the pump with a reduced cost which will be profitable. When the repair cost is higher or if the pump replacement is necessary, the profitability depends on the initial condition of the pump, the savings achieved with the improvement of upgrading and obviously on the cost. In general, booster pump repairs are less expensive than well pump repairs, given the same $\mathrm{kW}$ size.

Figure 8 shows a contour plot which relates Input kW and OPPE with potential savings obtained (in Thousand \$ per year) for the well and non-well pumps which can be improved (OPPE below the average of the group). Obviously, pumps with higher OPPE would have lower savings as a lower increment in efficiency improvement would be obtained. Additionally, there will be lower savings if the input power is low in both well and non-well pumps. This fact is clearer in case of non-well pumps.

For well pumps, high savings are observed in a range of Input power near $100 \mathrm{~kW}$ and also close to 250 $\mathrm{kW}$. When OPPE is around 50\% there is a range between 200 and $250 \mathrm{~kW}$ with high potential savings.

In the case of non-well pumps, the higher savings are related to initial OPPEs between 20 and 30\% for values over $130 \mathrm{~kW}$ of input power. Pumps with 50-55\% of OPPE and input powers over $200 \mathrm{~kW}$ also show high savings.
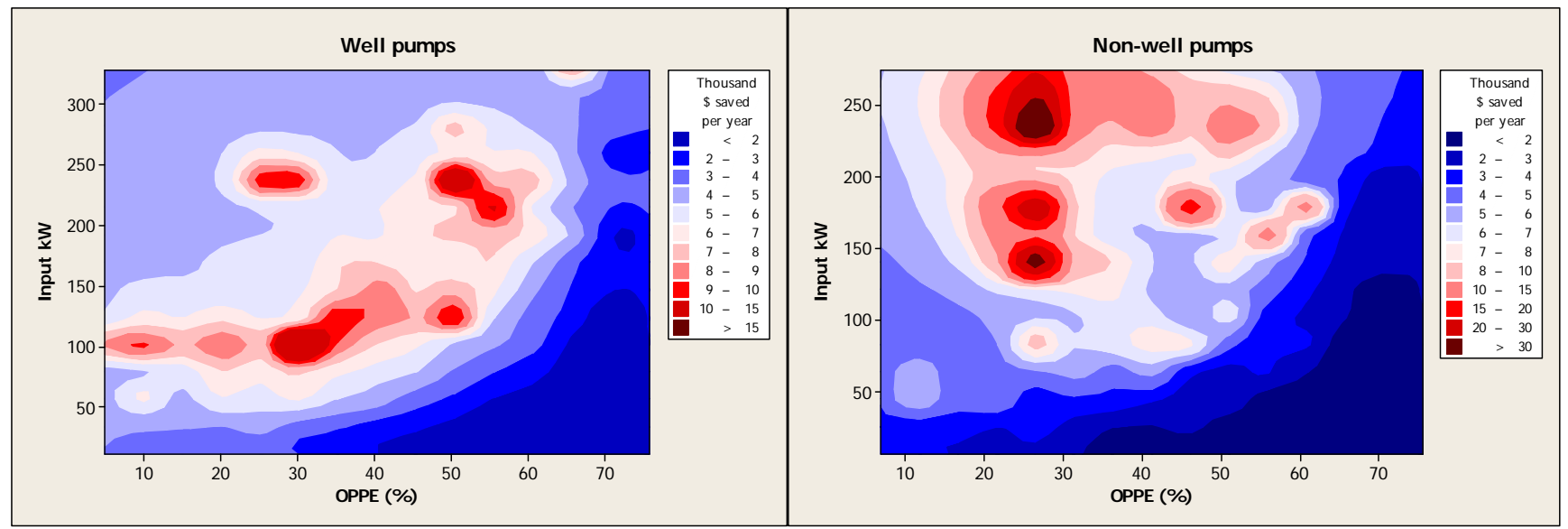

Figure 8. Contour plot of Input kW vs. OPPE (\%) arranged by money savings (Thousand \$/year)

\section{CONCLUSIONS}

1. The proportion of non-well pumps susceptible to improvements is slightly higher than for well pumps but more potential energy savings are obtained per well pump.

2. Well pumps with lower TDH and Q usually have poorer OPPE values. High flow rates and input power are typically associated with better OPPE values. 
3. Low values of OPPE are observed for non-well pumps with high Q and low TDH or pumps with low $\mathrm{Q}$ and high TDH. These pumps also tend to have higher annual energy consumption.

4. Big well pumps providing high flows and TDH do not necessarily have a higher annual energy consumption than other pump categories.

5. There was a wide range of OPPE for pumps with large annual energy consumption (MWh/year). This is interesting because one might assume that extra attention would be paid to OPPE, if there are large annual power bills.

6. Pumps with low annual energy consumption have lower-than-typical efficiencies.

7. In order to maximize energy savings by targeting the least number of pumps, those with high annual energy consumption should be the objective of improvements - especially well pumps with low TDH and input power or non-well pumps with low flow rate.

8. It is most economical to target pumps with high energy consumption and low input power (but operating many hours per year) as the motor size and pump size is usually relatively small and is therefore relatively inexpensive to modify.

\section{REFERENCES}

Burt, C.M., D. J. Howes, and G. Wilson. 2003. California Agricultural water electrical energy requirements. ITRC Report No. R 03-006. Irrigation Training and Research Center, California Polytechnic State University, San Luis Obispo, California, USA. 154 p.

Burt, C. M. and D.J. Howes. 2005. CEC Agricultural peak load reduction program final report. ITRC Report No. R 05-003. Irrigation Training and Research Center, California Polytechnic State University, San Luis Obispo, California, USA. 90 p.

Burt, C.M., X. Piao, F. Gaudi, B. Busch, and NFN Taufik. 2008. Electric motor efficiency under variable frequencies and loads. ASCE Journal Irrig. Drain. Engr 134(2):129-136.

Burt, C.M. and D.J. Howes. 2008. Irrigation district energy survey. ITRC Report No. R 08-002. Irrigation Training and Research Center, California Polytechnic State University, San Luis Obispo, California, USA.

Hanson, B.R. 1988. Benefits and costs of improving pumping efficiency. California Agriculture 42(4):21-22.

Hanson, B.R. 2002. Improving pumping plant efficiency does not always save energy. California Agriculture 56(4):123-127. 